\title{
Fate of aortic bioprostheses: An 18-year experience
}

\author{
Alessandro Piccardo, MD, Jean David Blossier, MD, Alexandre Le Guyader, MD, Isabelle Orsel, MD, \\ Seifeddine Sekkal, MD, Elisabeth Cornu, MD, and Marc Laskar, MD
}

\begin{abstract}
Objective: To report our experience in aortic valve replacement with the Mitroflow (Sorin, Vancouver, Canada) aortic bioprosthesis.

Methods: We retrospectively reviewed all patients who underwent aortic valve replacement with a Mitroflow bioprosthesis at our institution from January 1994 to December 2011. No exclusion criteria were retained. Patients were followed yearly. Echocardiography follow-up was performed systematically before the hospital discharge and annually by patients' cardiologists.
\end{abstract}

Results: Seven hundred twenty-eight patients (mean age, $76 \pm 6$ years; range, 33-91 years) underwent aortic valve replacement with Mitroflow 12A or LX model and were included in this analysis. 30-day mortality for nonemergent isolated aortic valve replacement was $5.5 \%$. Eight patients $(1 \%)$ underwent reoperation for structural valve deterioration (SVD) and 30 patients (5.8\%) presented echocardiographic signs of SVD. Actuarial freedom from reoperation for SVD was $99 \% \pm 0.5 \%$ and $95 \% \pm 5 \%$ at 10 and 15 years. Actuarial freedom from echocardiographic signs of SVD was $77 \% \pm 5 \%$ and $56 \% \pm 11 \%$ at 10 and 15 years, respectively. At the univariate analysis, only the mean gradient at discharge $(P=.0200)$, the prevalence of size $19(P=.0273)$, and severe patient-prosthesis mismatch $(P=.0384)$ were significantly different in patients developing SVD at follow-up. Freedom from echocardiographic signs of SVD at 8 years were $88 \% \pm 4 \%$ and $64 \% \pm 13 \%$ in patients with a Mitroflow $>19$ and Mitroflow 19 , respectively (log-rank test, $P=.0056$; Wilcoxon test, $P=.0589$ ).

Conclusions: Overall outcomes were satisfactory. However the risk of early SVD seems higher for the Mitroflow size 19. This size should be reserved for applications when annulus enlargement is risky or there is an anatomic contraindication to sutureless or stentless valve. (J Thorac Cardiovasc Surg 2016;151:754-61)

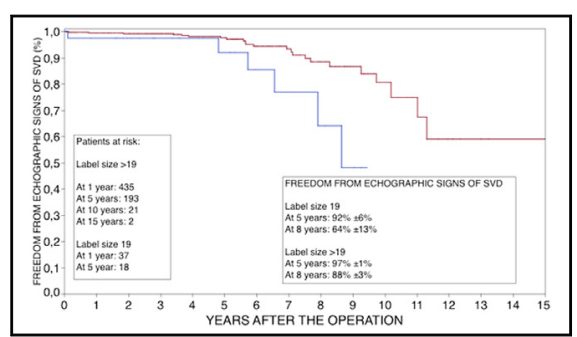

Freedom from structural valve deterioration (SVD) according to size of prosthesis.

\section{Central Message}

Overall outcomes were satisfactory. However the Mitroflow size 19 (Sorin, Vancouver, Canada) seems vulnerable to a higher risk of early degeneration.

\section{Perspective}

Mitroflow size 19 (Sorin, Vancouver, Canada) is presently the smallest biological stented valve available on the market. It is broadly employed in small annulus applications. However, Mitroflow size 19 seems vulnerable to a higher risk of early structural valve deterioration. This size should be reserved for applications when the annulus enlargement is risky or when there is an anatomic contraindication to sutureless or stentless valve.

See Editorial Commentary page 762 .
丹 Supplemental material is available online.

Important demographic changes are taking place in Western populations. In the European Union, according to Statistical Office of the European Communities, ${ }^{1}$ the octogenarian

From the Department of Thoracic and Cardiovascular Surgery, "Dupuytren" University Hospital, Limoges, France.

Received for publication May 21, 2015; revisions received June 30, 2015; accepted for publication Oct 6, 2015; available ahead of print Dec 2, 2015.

Address for reprints: Alessandro Piccardo, MD, Service de chirurgie thoracique et cardiovasculaire, CHU "Dupuytren," Ave Martin Luther King, 87000 Limoges, France (E-mail: alessandropiccardo@gmail.com).

0022-5223/\$36.00

Copyright (c) 2016 by The American Association for Thoracic Surgery

http://dx.doi.org/10.1016/j.jtcvs.2015.10.020 population has grown from $1.5 \%$ in 1960 to $4.8 \%$ in 2007 and is expected to reach 7.4\% in 2030 (Appendix E1).

As a result of the ageing population, during the past 15 years a higher number of elderly patients have been referred to cardiac surgery for aortic valve replacement. In these patients, biological prostheses are strongly recommended because they offer freedom from anticoagulant treatment and potentially lifelong durability resulting in a better event-free survival when compared with mechanical prostheses. Among the biological aortic valve prostheses currently available, the present design of the Mitroflow valve was introduced 1992 by the model 12A (Sorin, Vancouver, Canada). It is a bovine pericardial prosthesis specifically designed for improved hemodynamic parameters in small aortic annuli. In 2006, the model 12A was replaced by the LX without any modification in the design 


\section{Abbreviations and Acronyms \\ $\mathrm{NSD}=$ nonstructural dysfunction \\ PPM $=$ patient-prosthesis mismatch \\ $\mathrm{SVD}=$ structural valve deterioration}

and in the material components, so that model $12 \mathrm{~A}$ and model LX can be considered the same prosthesis.

The fate of Mitroflow bioprosthesis is unclear. Although published series reported satisfactory hemodynamic parameters and long-term durability, ${ }^{2-6}$ Senage and colleagues ${ }^{7}$ recently reported frequent early structural valve deterioration (SVD) and poor long-term survival after aortic valve replacement with the Mitroflow bioprosthesis and they recommended careful monitoring and urgent redo surgery in patients with severe SVD even in asymptomatic patients.

We report our experience in aortic valve replacement with the Mitroflow aortic bioprosthesis to analyze survival, occurrence of SVD, nonstructural valve dysfunction, and endocarditis after surgery.

\section{MATERIALS AND METHODS}

We retrospectively reviewed all patients who underwent aortic valve replacement with the Mitroflow bioprosthesis (12A and LX models) at our institution from January 1994 to December 2011. No exclusion criteria were retained. Morbidity and mortality after the aortic valve replacement were reported according the latest guidelines.

SVD was defined as a dysfunction or deterioration of the prosthesis (exclusive of thrombosis or infection) determined by reoperation or echocardiographic investigation. At the echocardiographic follow-up, the finding of a mean transprosthetic gradient $>40 \mathrm{~mm} \mathrm{Hg}$ or an aortic regurgitation more than moderate was considered SVD.

Nonstructural dysfunction (NSD) was defined as any abnormality not intrinsic to the valve itself that results in stenosis or regurgitation of the prosthesis (exclusive of thrombosis or infection).

Diagnosis of endocarditis was based on evidence of abscess, paravalvular leak, pus, vegetation at the reoperation (confirmed as secondary to infection by histologic or bacteriologic studies) or in absence of reoperation by the Duke Criteria for endocarditis.

The follow-up ended in April 2014. Patients were followed either by yearly outpatient visit or by telephone and letter to the referring physician. Echocardiography follow-up was realized systematically before hospital discharge and annually by patients' cardiologists.

\section{Statistical Analysis}

Statistical analysis was performed with JMP statistical analysis software (SAS Institute Inc, Cary, NC). Continuous variables are presented as means \pm standard deviation and categorical variables are expressed as frequencies.

For the univariate analysis, continuous variables were compared with the Student $t$ test or the Wilcoxon rank-sum test. Categorical variables were compared by means of the $\chi^{2}$ test or Fisher exact test $(2$ tailed) if the expected count in any cell was $<5$.

Completeness of the follow-up was calculated as the ratio of total observed person-time to potential person-time of follow-up to the closing date of the study (C index). ${ }^{8}$ Survival was determined by the Kaplan-Meier method and is expressed as the proportion \pm standard error. Survival was compared by log-rank and Wilcoxon tests.

\section{RESULTS \\ Populations}

During the study period, 728 patients (mean age, $76 \pm 6$ years; range, 33-91 years) underwent aortic valve replacement with Mitroflow model 12A or LX and were included in this analysis. Demographic characteristics, patients' history, and operative data are detailed in Table 1. Twenty-six percent of patients were octogenarians and $2 \%$ of patients were aged 60 years or younger. Half of patients were in New York Heart Association functional class III or IV. Indication for aortic valve replacement was symptomatic aortic stenosis in $91 \%$ of patients (661 patients) and pure aortic regurgitation in $9 \%$ of patients (67 patients). In 19 patients $(2.5 \%)$ the aortic regurgitation was related to endocarditis and in 2 patients $(0.3 \%)$ to a leaflet prolapse because of type A aortic dissection. Four percent of patients underwent emergency surgery. The left ventricular ejection fraction was unpaired in $20 \%$ of patients. Half of patients underwent concomitant procedure. No patients had an enlargement of the aortic annulus. Table 2 details distribution of prosthesis size in our population. The majority of patients received size 21 or size 23 , but size 19 was also frequent (10\% of patients). Based on the in vivo effective orifice area values given by the manufacturer of the Mitroflow valve, $4 \%$ of patients $(\mathrm{n}=30)$ had severe patient-prosthesis mismatch (PPM). Severe PPM was observed mostly with sizes 19 and $21 \mathrm{~mm}$ (Table 2).

\section{Survival and Morbidity}

Early mortality was $10.3 \%$ (75 patients), $12.5 \%$ (91 patients), and 13.7\% (100 patients) at 30, 60, and 90 days, respectively, after surgery. Thirty-day mortality for nonemergent isolated aortic valve replacement was $5.5 \%$ (20 of 359 patients). Cardiogenic shock and multiorgan failure were the main causes of early death (Table 3).

Two hundred four patients developed at least 1 complication after the surgery. Major bleeding and cardiogenic shock were the most frequent postoperative complications. Less than $3 \%$ of patients required pacemaker implantation for permanent atrioventricular block (Table 3).

There were 230 late deaths. Median survival was 7.4 years. Actuarial survival, including early deaths, was $66 \% \pm 2 \%, 33 \% \pm 3 \%$, and $15 \% \pm 7 \%$ at 5,10 , and 15 years, respectively, after initial surgery (Figure 1). Actuarial survival after nonemergent isolated aortic valve replacement was $72 \% \pm 2 \%$ and $40 \% \pm 4.5 \%$ at 5 and 10 years, respectively, after initial surgery (Figure 1).

\section{Reoperation}

During the study period (mean follow-up, $4.3 \pm 1.3$ years; median follow-up, 4 years; range, $0-16.3$ years; 3155.81 
TABLE 1. Baseline characteristics of the population

\begin{tabular}{|c|c|}
\hline Characteristic & Result \\
\hline Population, $\mathrm{n}$ & 728 \\
\hline Age (y) & $\begin{array}{l}76 \pm 6 \\
76(33-91)\end{array}$ \\
\hline Octogenarians & $194(26)$ \\
\hline Age $<60$ y & $11(1.5)$ \\
\hline Men & $420(57)$ \\
\hline Body surface area $\left(\mathrm{m}^{2}\right)$ & $1.81 \pm 0.23$ \\
\hline \multicolumn{2}{|l|}{ Patient history } \\
\hline High blood pressure & $531(73)$ \\
\hline Diabetes & $189(26)$ \\
\hline Dyslipidemia & $364(50)$ \\
\hline Chronic obstructive pulmonary disease & $80(11)$ \\
\hline Tobacco history & $65(9)$ \\
\hline New York Heart Association functional class III or IV & $320(44)$ \\
\hline Peripheral vascular disease & $43(6)$ \\
\hline Atrial fibrillation & $145(20)$ \\
\hline $\begin{array}{l}\text { Creatine clearance, Modification of Diet in Renal } \\
\text { Disease }(\mathrm{mL} / \mathrm{min})\end{array}$ & $74 \pm 24$ \\
\hline Creatine clearance $<30 \mathrm{~mL} / \mathrm{min}$ & $22(3)$ \\
\hline Stroke & $65(9)$ \\
\hline Redo cardiac surgery & $36(5)$ \\
\hline \multicolumn{2}{|l|}{ Echocardiographic data } \\
\hline Left ventricular ejection fraction $(\%)$ & $62 \pm 14$ \\
\hline$<50 \%$ & $145(20)$ \\
\hline$<35 \%$ & $29(4)$ \\
\hline Aortic surface area $\left(\mathrm{cm}^{2}\right)$ & $0.7 \pm 0.3$ \\
\hline Mean aortic gradient $(\mathrm{mm} \mathrm{Hg})$ & $43 \pm 20$ \\
\hline Systolic pulmonary arterial pressure (mm Hg) & $35 \pm 14$ \\
\hline Systolic pulmonary arterial pressure $>60 \mathrm{~mm} \mathrm{Hg}$ & $36(5)$ \\
\hline \multicolumn{2}{|l|}{ Operative data } \\
\hline Urgent or emergency surgery & $27(4)$ \\
\hline Associated procedure & $356(49)$ \\
\hline Associated coronary artery bypass grafting & $283(39)$ \\
\hline Cardiopulmonary bypass time (min) & $113 \pm 53$ \\
\hline Aortic crossclamp time (min) & $88 \pm 36$ \\
\hline
\end{tabular}

Values are presented as $n, n \pm$ standard deviation, median (range), or $n(\%)$.

patient-years; completeness of the follow-up, 721 of 728 [99\%]; and C index, 0.90) 18 patients $(2.3 \%)$ underwent reoperation for SVD, NSD, and endocarditis on the operated valve.

\section{Freedom from Reoperation for SVD}

Eight patients $(1 \%)$ underwent reoperation for SVD (linearized rate, $0.25 \%$ patients/year). Seven patients underwent conventional aortic valve replacement, 1 patient underwent transcatheter aortic valve implantation. No patient died during reoperation. The cause of SVD was leaflet calcification in all patients leading to a pure prosthesis stenosis in 4 patients and stenoinsufficiency in 4 patients. Actuarial freedom from reoperation for SVD was $99 \% \pm 0.5 \%, 95 \% \pm 5 \%$, and $95 \% \pm 5 \%$ at 5,10 , and 15 years, respectively, after initial surgery (Figure 2).

\section{Freedom from Reoperation for NSD}

Two patients $(0.3 \%)$ underwent reoperation for severe paravalvular leak within 6 months after the initial operation. Initial operation was aortic and mitral valve replacement in 1 patient and isolated aortic valve replacement in the other. They had no history of endocarditis and bacteriologic analysis of the prosthesis confirmed the absence of endocarditis. Operative mortality at the reoperation was $50 \%$. Actuarial freedom from reoperation for NSD was $99.8 \% \pm 0.2 \%$ at $1,5,10$, and 15 years, respectively, after the initial operation.

\section{Freedom from Reoperation for Endocarditis on the Operated Valve}

Eight patients (1\%) underwent reoperation for endocarditis on the operated valve. At the initial operation, no patient presented opaortic valve endocarditis. Two patients underwent reoperation within 6 months after the initial operation. Operative mortality at reoperation was $50 \%$. Actuarial freedom from reoperation for endocarditis on an operated valve was $98.7 \% \pm 0.5 \%, 98 \% \pm 0.5 \%$, and $98 \% \pm 0.5 \%$ at 5,10 , and 15 years, respectively, after initial surgery (Figure 3).

\section{Echocardiographic Follow-Up}

During the study period (mean follow-up, $5 \pm 2.7$ years; median follow-up, 4.7 years; range, $0-16.14$ years; 2326.2 patient-years; completeness of follow-up, 512 of 655 discharged patients [78\%]; and $\mathrm{C}$ index, 0.73) 35 patients $(6.8 \%)$ presented a mean transprosthetic gradient $>30 \mathrm{~mm} \mathrm{Hg}$ and 22 patients $(4.3 \%)$ presented prosthesis regurgitation more than mild. Among these, 30 patients $(5.8 \%)$ presented with SVD (linearized rate, $1.28 \%$ patients/y): 21 patients had a mean transprosthetic gradient $>40 \mathrm{~mm} \mathrm{Hg}, 7$ patients presented with prosthetic

TABLE 2. Prosthesis distribution, early postoperative mean gradient, and occurrence of patient-prosthesis mismatch (PPM)

\begin{tabular}{|c|c|c|c|c|c|}
\hline Valve size & n $(\%)$ & $\begin{array}{c}\text { Mean gradient at discharge } \\
\text { (mean } \mathbf{m m ~} \mathrm{Hg} \pm \text { standard deviation) }\end{array}$ & $\begin{array}{c}\text { Mean gradient at follow-up* } \\
\text { (mean } \mathbf{m m ~} \mathrm{Hg} \pm \text { standard deviation) }\end{array}$ & $\begin{array}{c}\text { Moderate PPM } \\
\text { n }(\%) \\
\end{array}$ & $\begin{array}{c}\text { Severe PPM } \\
\text { n }(\%)\end{array}$ \\
\hline 19 & $73(10)$ & $17 \pm 12$ & $19 \pm 8$ & $52(72)$ & $19(26)$ \\
\hline 21 & $238(32)$ & $14 \pm 5$ & $17 \pm 7$ & $193(81)$ & $10(4)$ \\
\hline 23 & 249 (34) & $12 \pm 5$ & $15 \pm 5$ & $166(66)$ & $1(0.4)$ \\
\hline 25 & $135(18.5)$ & $10 \pm 4$ & $13 \pm 6$ & $14(10)$ & 0 \\
\hline 27 & $33(4.5)$ & $8 \pm 2$ & $13 \pm 5$ & 0 & 0 \\
\hline
\end{tabular}

PPM, Patient-prosthesis mismatch. *Excluding patients with echocardiographic finding of structural valve deterioration. 
TABLE 3. Causes of early mortality and early postoperative complications

\begin{tabular}{lc}
\hline \multicolumn{1}{c}{ Variable } & $\begin{array}{c}\text { Results } \\
(\mathbf{n = 7 2 8})\end{array}$ \\
\hline Mortality $<30 \mathrm{~d}$ & $75(10.3)$ \\
Causes of early death & \\
Cardiogenic shock & $32(4.3)$ \\
Multiorgan failure & $16(2.2)$ \\
Embolism & $14(2)$ \\
$\quad$ Stroke & $8(1.1)$ \\
$\quad$ Mesenteric ischemia & $6(0.9)$ \\
Hemorrhagic shock & $7(0.9)$ \\
Sepsis & $6(0.8)$ \\
Early complications & $204(28)$ \\
Re-exploration for bleeding & $115(15.8)$ \\
Cardiogenic shock & $58(7.9)$ \\
Extracorporeal membrane oxygenation & $15(2)$ \\
Stroke & $11(1.5)$ \\
Mesenteric ischemia & $8(1)$ \\
Pacemaker implantation & $21(2.8)$ \\
Tracheotomy & $9(1.2)$ \\
Dialysis & $14(1.9)$ \\
Multiorgan failure & $22(3)$ \\
Mediastinitis & $7(0.9)$ \\
Sepsis & $47(6.4)$ \\
\hline Values are presented as n $(\%)$ &
\end{tabular}

Values are presented as $\mathrm{n}(\%)$.

regurgitation more than moderate without significant prosthesis stenosis, and 2 patients presented with a transprosthetic gradient $>40 \mathrm{~mm} \mathrm{Hg}$ associated with a regurgitation more than moderate. Actuarial freedom from SVD was $97 \% \pm 2 \%, 77 \% \pm 5 \%$, and $56 \% \pm 11 \%$ at 5,10 , and 15 years, respectively, after initial surgery (Figure 4). Table 2 details mean transprosthetic gradient at the follow-up, according to prosthesis size.
Freedom from SVD was significant different according to severity of PPM (log-rank test, $P=.0023$; Wilcoxon test, $P=.0007)$. Freedom from SVD at 8 years was $63 \% \pm 16 \%$ and $95 \% \pm 4 \%$ in patients with a severe PPM and no PPM, respectively (Figure 5).

In patients implanted with a Mitroflow size 19, freedom from SVD was significantly lower (log-rank test, $P=.0056$; Wilcoxon test, $P=.0589$ ). Freedom from SVD at 10 years were $88 \% \pm 4 \%$ and $64 \% \pm 13 \%$ in patients with a Mitroflow $>19$ and Mitroflow 19, respectively (Figure 6). Table 4 details univariate analysis for SVD. Only the mean transprosthetic gradient at discharge $(P=.0200)$, the prevalence of size 19 $(P=.0273)$, and the prevalence of severe PPM $(P=.0384)$ were significantly different in patients developing SVD at the follow-up.

\section{DISCUSSION}

The actual design of the Mitroflow was introduced in 1992 with the model 12A. In 2011, Sorin (now LivaNova PLC) released the model DLA introducing an antimineralization treatment with a solution of 1.2 octanediol. Model DLA was not included in this analysis. Published series reported satisfactory long-term durability with models $12 \mathrm{~A}$ and LX. When implanted in an elderly population, freedom from reoperation for SVD is estimated between $85 \%$ and $92 \%$ at 10 years and the linearized rate of reoperation between $0.56 \%$ and $1 \%$ of patients per year (Table 5). In our experience, during a mean follow-up of $4.3 \pm 1.3$ years, $1 \%$ of patients ( 8 out of 728 ) required reoperation for SVD. Freedom from reoperation was $95 \% \pm 5 \%$ at 10 years with a linearized rate of $0.25 \%$ of patients per year. This finding compares well with the

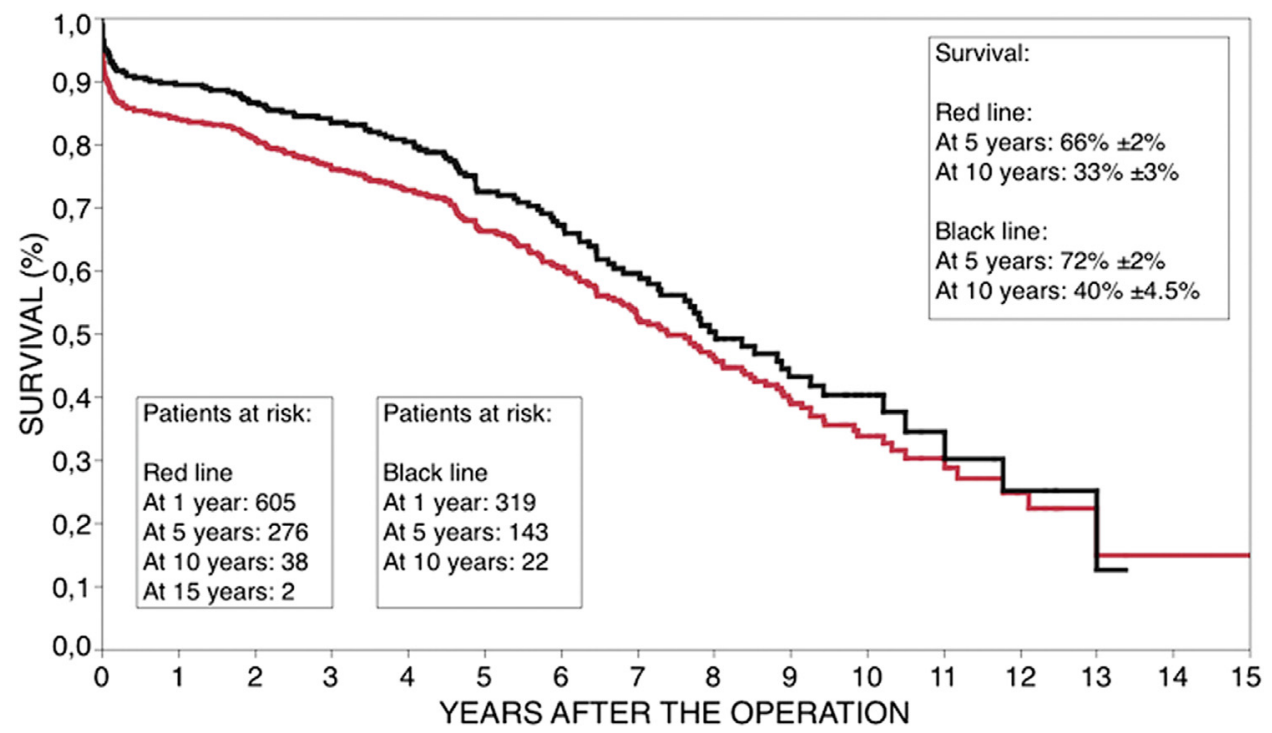

FIGURE 1. Overall survival after aortic valve replacement with the Mitroflow (Sorin, Vancouver, Canada) aortic bioprosthesis, showing nonemergent isolated aortic valve replacement (black line) and the overall population (red line). 


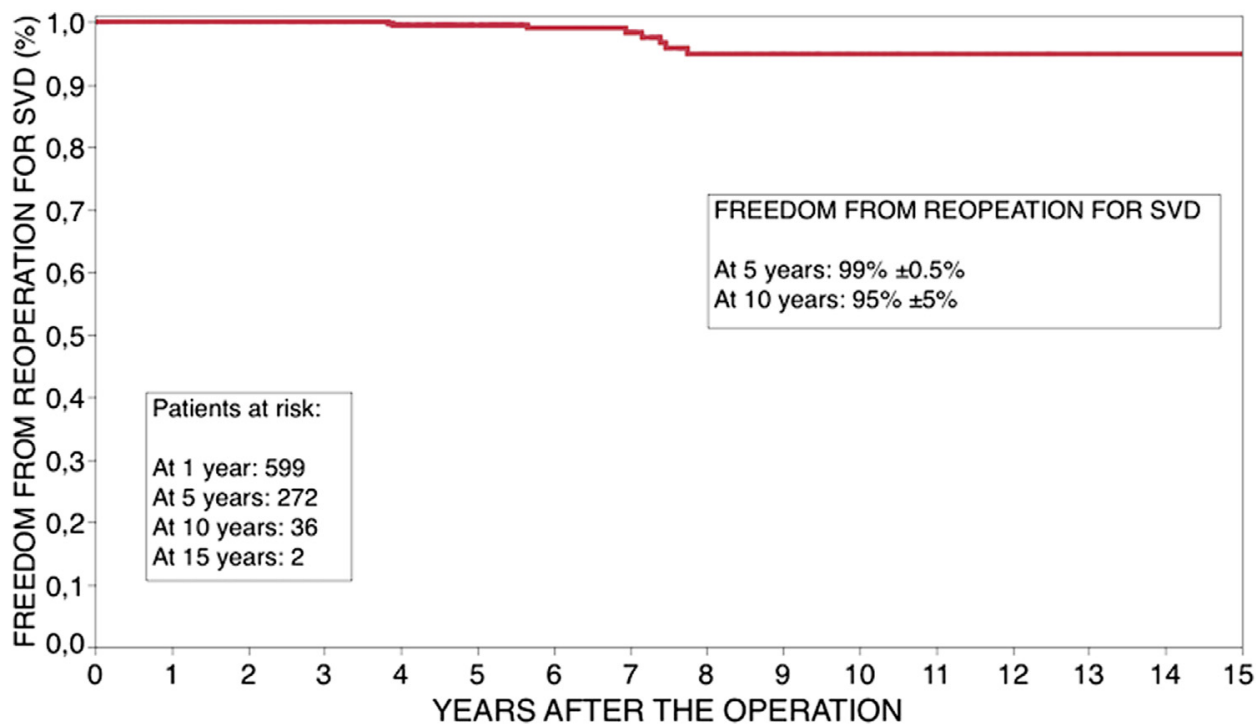

FIGURE 2. Freedom from reintervention for structural valve deterioration after aortic valve replacement with Mitroflow (Sorin, Vancouver, Canada) aortic bioprosthesis. SVD, Structural valve deterioration.

published durability of other aortic bioprostheses available in the market. In a recent large series on patients implanted with the Mosaic aortic bioprosthesis (Medtronic Inc, Minneapolis, Minn), Anselmi and colleagues ${ }^{9}$ reported $99 \%$ of freedom from reoperation for SVD at 10 years, after a mean follow-up of 8 years.

Ruggieri and colleagues ${ }^{10}$ reported $98 \%$ of freedom from reoperation for SVD at 10 years in patients implanted with Carpentier-Edwards Supra Annular porcine valve (Edwards Life-sciences, Irvine, Calif), after a mean follow-up of 13 years.
McClure and colleagues ${ }^{11}$ reported $97 \%$ of freedom from reoperation for SVD at 10 years, after CarpentierEdwards bovine pericardial prosthesis implantation, during a mean follow-up of 8 years.

However, in elderly populations, the analysis of reoperation rate can underestimate the real occurrence of significant SVD at follow-up. In octogenarians, the clinical influence of SVD can be difficult to assess and it may delay the time of surgery. Moreover, because of the high prevalence of comorbidities, the estimated operative risk could be high and play a role in avoidance of redo surgery

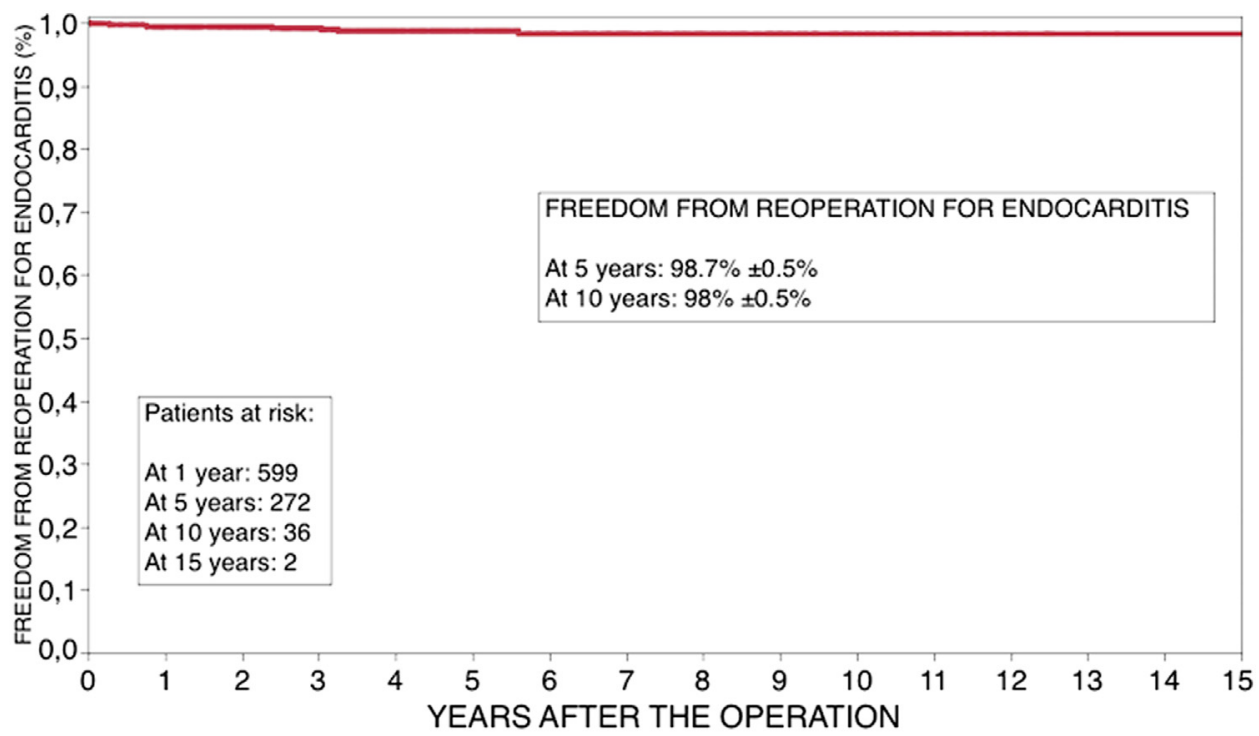

FIGURE 3. Freedom from reoperation for endocarditis on operated valve after aortic valve replacement with Mitroflow (Sorin, Vancouver, Canada) aortic bioprosthesis. 


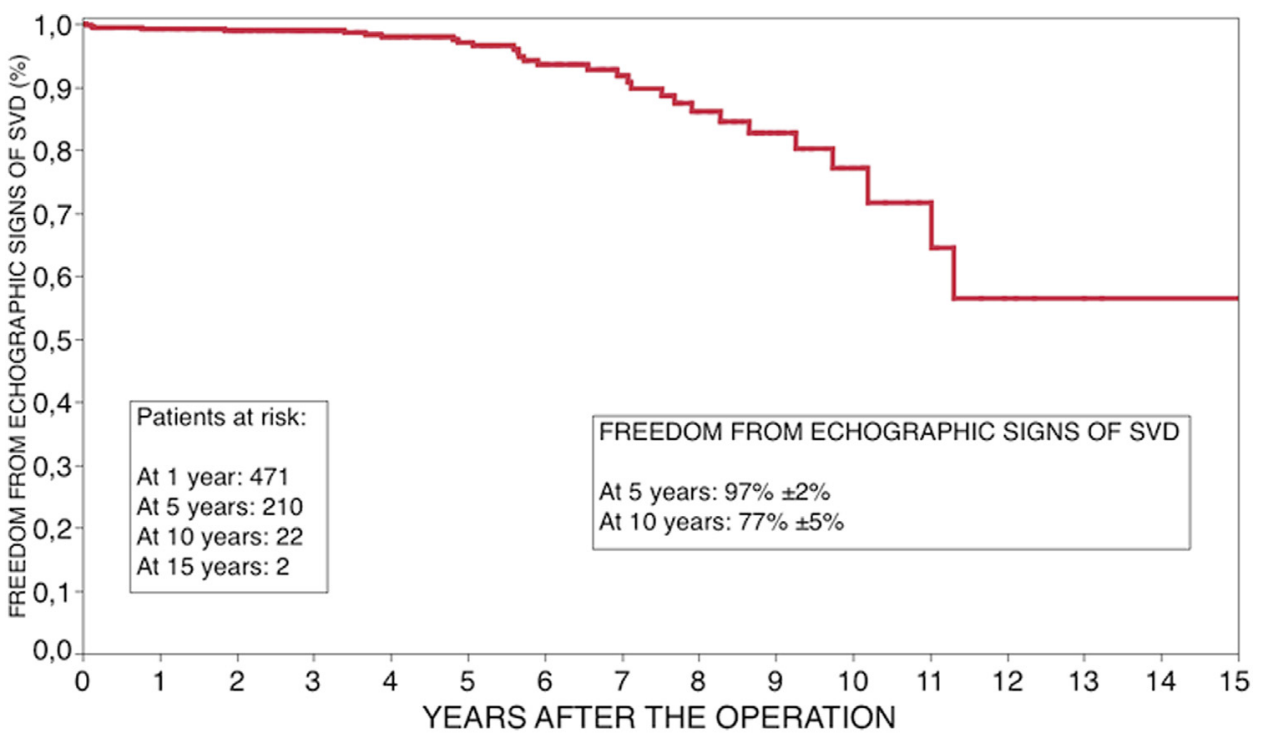

FIGURE 4. Freedom from echocardiographic signs of structural valve deterioration (SVD) (ie, mean transprosthetic gradient $>40 \mathrm{~mm} \mathrm{Hg}$ or aortic regurgitation greater than mild) after aortic valve replacement with Mitroflow (Sorin, Vancouver, Canada) aortic bioprosthesis.

in these patients. Echocardiographic follow-up should always be reported to better define the durability of the prosthesis. The Italian study on the Mitroflow postoperative results group ${ }^{6}$ reported the first long-term echocardiographic follow-up on Mitroflow bioprosthesis. Using the same echocardiographic criteria we adopted in our study, they found a freedom from SVD of approximately $90 \%$ at 10 years (mean age, $75.3 \pm 6.8$ years; median followup, 5.15 years; 7447 patient-years; and $0.9 \%$ of patients per year). Recently, Senage and colleagues ${ }^{7}$ published a large echocardiographic follow-up on Mitroflow prosthesis. In their series, $6 \%$ of patients (39 out of 617) experienced an SVD during the follow-up. A third of SVDs were early and freedom from SVD was $91.6 \%$ at 5 years (mean age, $76.1 \pm 6.3$ years; mean follow-up, $3.8 \pm 2$ years, patientyears not reported; and patients per year were not reported). In our experience, $5.8 \%$ of patients (30 out of 512) presented an echocardiographic sign of SVD during the follow-up but early durability was better: freedom from SVD was $97 \% \pm 2 \%$ at 5 years and $77 \% \pm 5 \%$ at 10 years

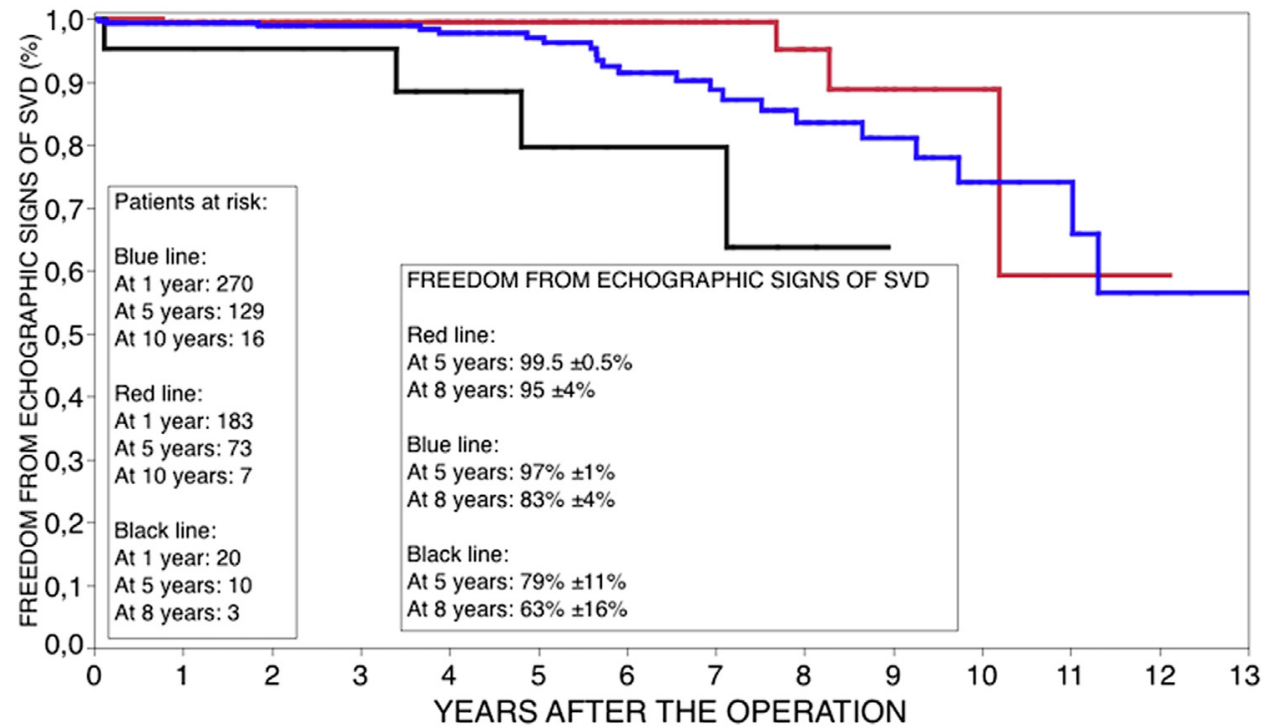

FIGURE 5. Freedom from echocardiographic signs of structural valve deterioration (SVD) (ie, mean transprosthetic gradient $>40 \mathrm{~mm} H \mathrm{Hg}$ or aortic regurgitation greater than mild) after aortic valve replacement with Mitroflow (Sorin, Vancouver, Canada) aortic bioprosthesis, according to severe (black line), moderate (blue line), or no (red line) patient-prosthesis mismatch. 


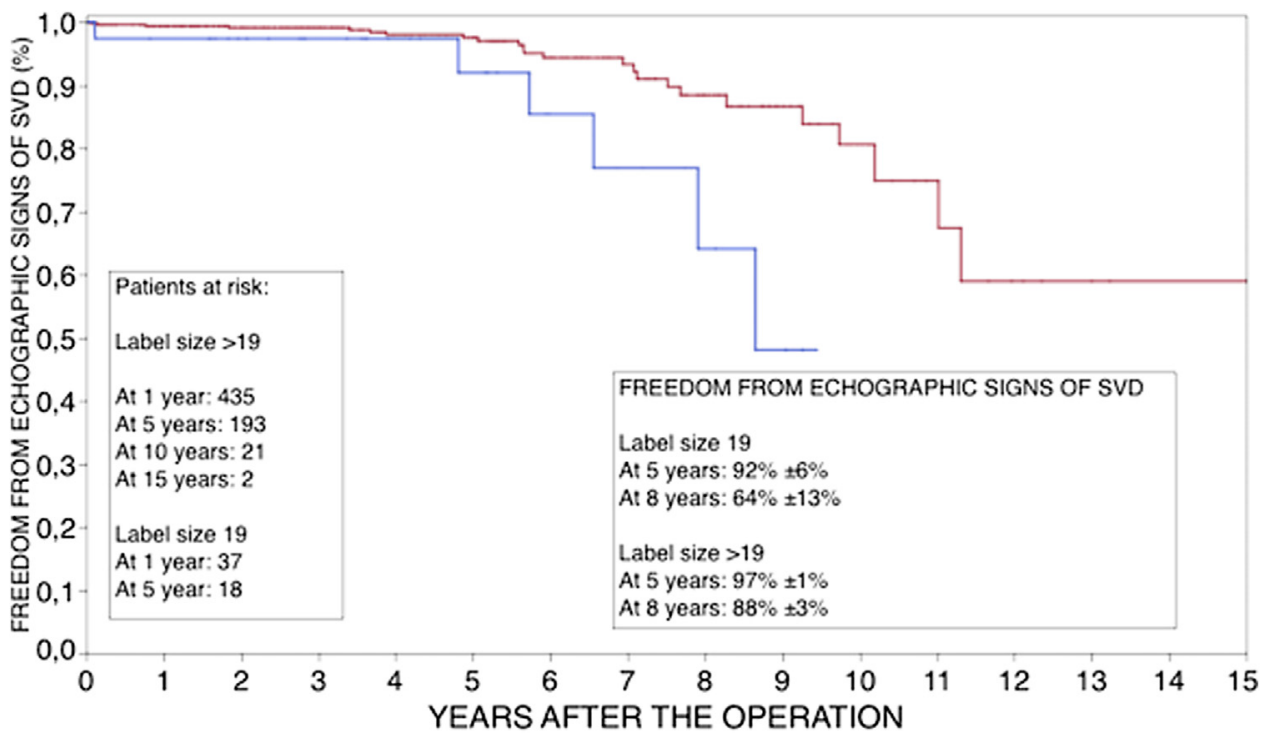

FIGURE 6. Freedom from echocardiographic signs of structural valve deterioration (SVD) (ie, mean transprosthetic gradient $>40 \mathrm{~mm} \mathrm{Hg}$ or aortic regurgitation greater than mild) after aortic valve replacement with Mitroflow (Sorin, Vancouver, Canada) aortic bioprosthesis, according to prosthesis size 19 (blue line) or size $>19$ (red line).

(mean follow-up, $5 \pm 2.7$ years; median follow-up, 4.7 years; range, $0-16.14$ years; completeness of followup, 512 out of 655 discharged patients [78\%]; 2326.2 patient-years; and $\mathrm{C}$ index, 0.73).

Our results outline interactions between prosthesis size and long-term durability. These findings are confirmed by Senage and colleagues ${ }^{6}$ and in a large, prospective study reporting a most pronounced trend of increasing gradient over time in the smaller-size valve. ${ }^{2}$ Based on a review of the literature, published series with a lower prevalence of

TABLE 4. Univariate analysis for structural valve deterioration (SVD) after aortic valve replacement with Mitroflow (Sorin, Vancouver, Canada) aortic bioprosthesis

\begin{tabular}{lccc}
\hline \multicolumn{1}{c}{ Variable } & $\begin{array}{c}\text { SVD } \\
(\mathbf{n}=\mathbf{3 0})\end{array}$ & $\begin{array}{c}\text { Not SVD } \\
(\mathbf{n}=\mathbf{4 8 2})\end{array}$ & $\boldsymbol{P}$ value \\
\hline Demographic characteristic & & & \\
$\quad$ Age (y) & $74 \pm 6$ & $76 \pm 6$ & .2096 \\
Age $<60 \mathrm{y}$ & $1(3.5)$ & $6(1)$ & .4131 \\
Octogenarian & $6(20)$ & $121(25)$ & .5207 \\
Men & $13(43)$ & $279(58)$ & .1206 \\
$\quad$ Body surface area $\left(\mathrm{m}^{2}\right)$ & $1.83 \pm 0.2$ & $1.81 \pm 0.2$ & .5684 \\
Operative data & & & \\
$\quad$ Emergency surgery & $2(6.5)$ & $12(2.5)$ & .2426 \\
$\quad$ Endocarditis & $2(6.5)$ & $7(1.5)$ & .0980 \\
Associated procedures & $12(40)$ & $222(46)$ & .5164 \\
Size 19 & $6(20)$ & $34(7)$ & .0273 \\
Echocardiographic data & & & \\
$\quad$ Mean gradient at discharge (mm Hg) & $17 \pm 6$ & $12.5 \pm 6$ & .0200 \\
$\quad$ Moderate patient-prosthesis & $22(73)$ & $272(56.5)$ & .0626 \\
$\quad$ mismatch & & & \\
$\quad$ Severe patient-prosthesis mismatch & $4(13)$ & $18(3.5)$ & .0384 \\
\hline Values are presented as mean \pm standard deviation or $\mathrm{n}(\%) . S V D$, Structural valve \\
deterioration.
\end{tabular}

small prosthesis reported better durability. Asch and colleagues ${ }^{2}$ in their multicenter prospective study reported $2 \%$ of prosthesis size 19 and $98 \%$ of freedom from SVD at 5 years. On the contrary, Senage and colleagues ${ }^{6}$ reported $22 \%$ of prosthesis size 19 and $91 \%$ of freedom from SVD at 5 years. Flameng and colleagues ${ }^{12}$ extensively investigated interaction between prosthesis size and SVD. They suggested that SVD could be accelerated in small prostheses because the consequent prosthesis mismatch could induce abnormal flow profiles and changes in stress distribution facilitating the calcification process.

The management of a small aortic annulus is still a matter of debate. Enlargement of the annulus has been proposed to reduce the risk of PPM. However, this procedure seems to be associated with a higher mortality rate ${ }^{13-15}$ and the benefit in elderly patients who live a sedentary life is limited.

Mitroflow size 19 is presently the smallest biological stented valve available on the market. Because of its excellent hemodynamic performance (confirmed also by our study), this valve is broadly employed in small annuli when enlargement of the aortic annulus is risky. As a consequence, Mitroflow series when compared with the other valves series, are characterized by a higher prevalence of very small prosthesis that are at risk of accelerated SVD. Comparison of the durability among the valves should take into consideration this potential selection bias.

The model $12 \mathrm{~A}$ and LX are no more available on the market. They have been replaced by the third generation of Mitroflow, which introduced an antimineralization treatment. Even if overall durability is expected to be 
TABLE 5. Freedom from reoperation for structural valve deterioration according to the recent published series

\begin{tabular}{|c|c|c|c|c|c|c|c|}
\hline Series and patients & $\begin{array}{c}\text { Mean } \\
\text { age }(y)\end{array}$ & Size $19(\%)$ & Follow-up (y) & $\begin{array}{c}\text { Cumulative } \\
\text { follow-up } \\
\text { (patient-years) }\end{array}$ & $\begin{array}{c}\text { Reoperation } \\
\text { rate }(\%)\end{array}$ & $\begin{array}{l}\text { Freedom from } \\
\text { reoperation }\end{array}$ & $\begin{array}{c}\text { Linearized } \\
\text { rate }(\% \text { patients } / y)\end{array}$ \\
\hline $\begin{array}{l}\text { Asch and colleagues } \\
\quad(\mathrm{n}=276)\end{array}$ & 73.6 & 2.1 & $4 \pm 1.7$ & 1102 & 2.1 & At $5 \mathrm{y}: 97.8 \%$ & 0.56 \\
\hline $\begin{array}{l}\text { Jamieson and colleagues } \\
\qquad(\mathrm{n}=381)\end{array}$ & 76.4 & 9.5 & $5.4 \pm 3.4$ & 2048.7 & 4.2 & At 10 y: $85.6 \% \pm 3.8 \%$ & 0.79 \\
\hline $\begin{array}{l}\text { Joshi and colleagues } \\
\qquad(\mathrm{n}=275)\end{array}$ & $\mathrm{nr}$ & $\mathrm{nr}$ & $\mathrm{nr}$ & $\mathrm{nr}$ & 5.4 & At $10 \mathrm{y}: 92.5 \%$ & $\mathrm{nr}$ \\
\hline $\begin{array}{l}\text { Yankah and colleagues } \\
\quad(\mathrm{n}=1513)\end{array}$ & 73.2 & 13.5 & $4.07 \pm 0.12$ & 6163.5 & 4.2 & At $20 \mathrm{y}: 62.3 \% \pm 5.02 \%$ & 1 \\
\hline
\end{tabular}

better, ${ }^{16}$ we believe that because of the very small size, the risk of early degeneration still remains high for the Mitroflow size 19. This size should be reserved for use when annulus enlargement is risky or when there is an anatomic contraindication to use of a sutureless or stentless valve.

\section{Conflict of Interest Statement}

Authors have nothing to disclose with regard to commercial support.

\section{References}

1. EUROSTAT. http://ec.europa.eu/eurostat. Accessed October 21, 2015

2. Asch FM, Heimansohn D, Doyle D, Dembitsky W, Ferdinand FD, Swanson J, et al. Mitroflow aortic bioprosthesis 5-year follow-up: North American prospective multicenter study. Ann Thorac Surg. 2012;94:1198-203.

3. Jamieson WR, Koerfer R, Yankah CA, Zittermann A, Hayden RI, Ling H, et al. Mitroflow aortic pericardial bioprosthesis-clinical performance. Eur J Cardiothorac Surg. 2009;36:818-24.

4. Joshi V, Prosser K, Richens D. Early prosthetic valve degeneration with Mitroflow aortic valves: determination of incidence and risk factors. Interact Cardiovasc Thorac Surg. 2014;19:36-40.

5. Yankah CA, Pasic M, Musci M, Stein J, Detschades C, Siniawski H, et al. Aortic valve replacement with the Mitroflow pericardial bioprosthesis: durability results up to 21 years. J Thorac Cardiovasc Surg. 2008;136:688-96.

6. ISTHMUS Investigators. The Italian study on the Mitroflow postoperative results (ISTHMUS): a 20-year, multicentre evaluation of Mitroflow pericardial bioprosthesis. Eur J Cardiothorac Surg. 2011;39:18-26.

7. Sénage T, Le Tourneau T, Foucher Y, Pattier S, Cueff C, Michel M, et al. Early structural valve deterioration of mitroflow aortic bioprosthesis: mode, incidence, and impact on outcome in a large cohort of patients. Circulation. 2014;130 2012-20.

8. Clark TG, Altman DG, De Stavola BL. Quantification of the completeness of follow-up. Lancet. 2002;359:1309-10.

9. Anselmi A, Flécher E, Ruggieri VG, Harmouche M, Langanay T, Corbineau H, et al. Long-term results of the Medtronic Mosaic porcine bioprosthesis in the aortic position. J Thorac Cardiovasc Surg. 2014;147:1884-91.

10. Ruggieri VG, Flecher E, Anselmi A, Lelong B, Corbineau H, Verhoye JP, et al. Long-term results of the Carpentier-Edwards supraannular aortic valve prosthesis. Ann Thorac Surg. 2012;94:1191-7.

11. McClure RS, Narayanasamy N, Wiegerinck E, Lipsitz S, Maloney A, Byrne JG, et al. Late outcomes for aortic valve replacement with the Carpentier-Edwards pericardial bioprosthesis: up to 17-year follow-up in 1,000 patients. Ann Thorac Surg. 2010;5:1410-6.

12. Flameng W, Herregods MC, Vercalsteren M, Herijgers P, Bogaerts K, Meuris B. Prosthesis-patient mismatch predicts structural valve degeneration in bioprosthetic heart valves. Circulation. 2010;121:2123-9.

13. Dalichau H, Hannekum A, Niehues B, Irion A, Herse B. Hemodynamic and angiographic late results following enlargement of narrow aortic root using autologous pericardium in prosthetic aortic valve replacement. Thorac Cardiovasc Surg. 1985;33:288-95.

14. Sommers KE, David TE. Aortic valve replacement with patch enlargement of the aortic annulus. Ann Thorac Surg. 1997;63:1608-12.

15. Kulik A, Al-Saigh M, Chan V, Masters RG, Bedard P, Lam BK, et al. Enlargement of the small aortic root during aortic valve replacement: is there a benefit? Ann Thorac Surg. 2008;85:94-100.

16. Flameng W, Rega F, Vercalsteren M, Herijgers P, Meuris B. Antimineralization treatment and patient-prosthesis mismatch are major determinants of the onse and incidence of structural valve degeneration in bioprosthetic heart valves. J Thorac Cardiovasc Surg. 2014;147:1219-24.

Key Words: aortic valve, replacement, surgery, complications 
APPENDIX E1. Octogenarian population in the European Union ${ }^{1}$

\begin{tabular}{lcrc}
\hline Year & Total population & Age $\geq \mathbf{8 0}$ y & $\%$ \\
\hline 1960 & $250,624,785$ & $3,821,385$ & 1.52 \\
1970 & $271,517,342$ & $5,079,602$ & 1.87 \\
1980 & $284,858,356$ & $6,612,107$ & 2.32 \\
1990 & $292,673,202$ & $9,721,637$ & 3.32 \\
2000 & $304,261,341$ & $10,913,818$ & 3.58 \\
$2010 *$ & $319,586,172$ & $16,188,641$ & 5.06 \\
$2020 *$ & $330,668,717$ & $20,776,760$ & 6.28 \\
$2030 *$ & $335,550,827$ & $24,868,286$ & 7.41 \\
\hline
\end{tabular}

Data from 12 European Union countries, including Belgium, Germany (including ex-German Democratic Republic from 1991), Ireland, Greece, Spain, Metropolitan France, Italy, Grand Duchy of Luxembourg, Netherlands, Austria, Portugal, and Finland. *Population projection, convergence year 2150. 